\title{
Diagnostic TCD for intracranial stenosis in acute stroke patients: experience from a tertiary care stroke center in Karachi, Pakistan
}

\author{
Ayeesha Kamran Kamal ${ }^{*}$, Hasan Rehman², Nasir Mustafa², Bilal Ahmed ${ }^{3}$, Mohammad Jan, Faisal Wadivalla ${ }^{2}$ \\ and Syed Kamran²
}

\begin{abstract}
Background: Stroke is a common cause of morbidity and mortality around the world. Intracranial large artery atherosclerosis (ICAD) is a frequent etiology of stroke in the South Asian population. There is a need for widely available screening tools to identify patients that are at high risk of stroke due to ICAD for aggressive risk management. This study describes the experience of using the transcranial Doppler (TCD) as a screening tool for this purpose at a tertiary care hospital in a developing country.

Methods: 86 Patients admitted with stroke due to ICAD underwent TCD for six arteries (Right and left middle cerebral arteries, right and left anterior cerebral arteries, right and left posterior cerebral arteries) in addition to the magnetic resonance angiography (MRA) that is done routinely at the stroke center. Arteries were labeled with either $<50$ or $>50 \%$ stenosis by TCD using two separate criteria. These findings were compared with those from the MRA which was used as the gold standard. The proportion of patients that had complete exams (all six arteries insonated by TCD) was reported. The success rate of each TCD criteria in detecting arteries with $>50 \%$ stenosis was also calculated.

Results: There was an attempt to visualize 516 arteries (86 patients with 6 arteries each) of which 375 (72.7\%) were successfully insonated. 38 of the 86 (55.8\%) patients had complete examinations. MRA reported 43 (8.3\%) arteries as stenosed $>50 \%$. The TCD did not categorize any artery as stenosed using either criterion and hence failed to classify any stenosed artery correctly. The positive predictive and sensitivity was 0 for this study and the negative predictive value was $93.3 \%$.
\end{abstract}

Conclusions: This study indicates the poor sensitivity of TCD to be a reliable screening tool for the presence of ICAD in the South Asian population in a real life clinical setting.

Keywords: Transcranial Doppler, Intracranial stenosis, Magnetic resonance angiography, Cerebral infarction prevention, Cerebrovascular accident

\section{Background}

Stroke is a leading cause of morbidity and mortality worldwide resulting in an estimated 4.4 million deaths each year [1]. Large vessel intracranial atherosclerotic

\footnotetext{
*Correspondence: ayeesha.kamal@aku.edu

1 Stroke Service, Stroke Fellowship Program, International Cerebrovascular Translational Clinical Research Training Program, Fogarty International Center and The National Institute of Neurologic Disorders and Stroke, Section of Neurology, Department of Medicine, Aga Khan University, Stadium Road, Karachi 74800, Pakistan

Full list of author information is available at the end of the article
}

disease (ICAD) is believed to have a higher frequency among the South Asians [2-7] with one study [8] reporting it to be responsible for at least $30-50 \%$ strokes among the Asian population.

The pathophysiology of ischemic stroke revolves around atherosclerotic plaque formation over a number of years in the arteries of the Circle of Willis before the final cerebrovascular event. This event is presumably caused by a rupture of that plaque or progressive hemodynamic stenosis leading to decompensated low flow state with failure of the collaterals $[9,10]$. 
Regardless of the mechanism of stroke, prevention is the key to reduce mortality [11]. Studies such as WASID study [12] have identified medications that are beneficial in high risk patients. However, to identify intracranial stenosis there need to be screening tools that are not only effective but also widely available at an affordable cost to make them relevant to low income countries where this condition is prevalent.

The gold standard to detect large artery intracranial stenosis is conventional cerebral angiography [13] but the cost, unavailability and risk of stroke [14-17] make it impractical for screening purposes. Similarly magnetic resonance angiography (MRA) is not considered a viable option due to its high cost and availability issues [18]. Due to its wide availability, significantly less cost and non-invasiveness, the transcranial Doppler sonography (TCD) is considered a potentially valuable screening tool [19]. Previous studies that have looked at this diagnostic modality have shown encouraging results by reporting negative predictive values and sensitivities comparable to that of the MRA [20].

However, the majority of these studies have been performed on the Western population. Hence, this study aims to explore the viability of the TCD in this region as a screening tool to detect intracranial atherosclerotic disease in a real life low middle income country clinical setting.

\section{Methods}

\section{Study setting}

This study was conducted in a tertiary care hospital in Karachi, a metropolitan city located in the south of Pakistan with a multiethnic population of more than 13 million persons [21]. The hospital has its own stroke team and is equipped with MRA and TCD facilities along with on call radiologists round the clock.

\section{Selection of participants}

All patients admitted to this center after being diagnosed with stroke between January 2012 and January 2013 were eligible for this study. Participants were men and women aged $>18$ years who presented to the Emergency Department and were subsequently diagnosed with stroke due to atherosclerotic disease via CT scan or MRI. Participants had to consent to TCD in addition to routine MRA which is done as part of standard of care of every patient admitted with stroke at this center.

Patients were excluded from participation if they had concomitant acute coronary syndrome or any extracranial vascular disease. Any patient who refused consent was also excluded.

\section{Data collection instruments}

Relevant demographic data including, age and gender was extracted from the medical records available.

The subtype of stroke was determined using the causative classification system for ischemic stroke (CCS) [22].

The MRA was interpreted on digital images and the degree of stenosis was calculated using the following equation [13]:

$$
\% \text { stenosis }=\left[1-\left(D_{\text {stenosis }} / D_{\text {normal }}\right)\right] \times 100
$$

Using the degree of stenosis, the artery was then classified as normal or with mild atherosclerotic changes, moderately stenosed and severely stenosed or occluded. A normal artery had $<30 \%$ stenosis, a moderately stenosed artery had $30-50 \%$ stenosis and a severely stenosed artery was defined as an artery with $>50 \%$ stenosis. The severely stenosed artery was used as the outcome of interest since the WASID study [12] had defined this as the critical value beyond which there is proven benefit of antiplatelet therapy. The MRA was used as the gold standard since catheter angiography was considered too invasive for the purpose of this study.

All the TCDs were performed and reported by the same sonographer who had received training in this field. He was blinded to the MRA findings and was required to report the peak velocity (PV) and the time averaged mean of the maximum velocity (MV) for the following arteries: the right middle cerebral artery (RMCA), the left middle cerebral artery (LMCA), the right anterior cerebral artery (RACA), the left anterior cerebral artery (LACA), the right posterior cerebral artery (RPCA) and the left posterior cerebral artery (LPCA). The vertebral and the basilar arteries were excluded.

Using the TCD, intracranial stenosis was categorized as $>50$ or $<50 \%$. There were two criteria that were used for this purpose. The first criterion used the mean velocity (MV) while the second criterion used the peak velocity (PV). Both criteria were used independently and results using each criterion are reported.

Using the MV, any artery with a time averaged mean of the maximum velocity of $>100 \mathrm{~m} / \mathrm{s}$ was considered to have $>50 \%$ stenosis. This value was chosen taking into consideration the findings of the SONIA trial [20].

Using the peak velocity to determine the degree of stenosis, the criterion verified by Baumgartner et al. [23] was used which was slightly more complex. The cut offs for the peak velocity for $>50 \%$ stenosis were as follows: for the MCAs $>220 \mathrm{~cm} / \mathrm{s}$; for the PCAs $>145 \mathrm{~cm} / \mathrm{s}$; For the ACAs $>155 \mathrm{~cm} / \mathrm{s}$.

As in the SONIA trial [20], the standards set by the Intersocietal Commission for the Accreditation of 
Vascular Laboratories (ICAVL) [24] were followed for the TCD. Details of these standards are given in Additional file 1: Appendix 1.

\section{Statistical considerations}

The findings of the MRA were compared to those from the TCD to calculate the sensitivity, the positive predictive value and the negative predictive value of the TCD.

Sensitivity $=$ true positive/(true positive + false negative) [25].

Negative predictive value $=$ true negative/(true negative + false negative) [25].

All data was entered and analyzed via SPSS v19. Statistical analysis were reviewed by a biostatistician.

\section{Ethical considerations}

Prior to obtaining data, the study protocol was approved by the Ethical Review Committee of the Aga Khan University Hospital. No financial incentives were provided to any study participant. Written informed consent and verbal assent was given by all participants or their legal surrogate respondents prior to the investigation.

\section{Results}

There were a total of 86 patients who were enrolled in the study. 45 (52\%) were male while 41 (48\%) were female. The mean age for male patients was 57 (SD: 16) while the mean age for female patients was 60 (SD: 14). 97.7\% patients $(\mathrm{n}=84)$ had suffered from an ischemic stroke while only $2.3 \%(n=2)$ had a hemorrhagic stroke.

Among the 86 patients enrolled in the study, all 6 arteries (LACA, RACA, LMCA, RMCA, LPCA, RPCA) were found normal in $55(63.9 \%)$ of the patients as detected by the MRA while the remaining 31 patients had at least one diseased artery.

In all, 516 arteries (86 patients with 6 arteries each) were looked at and the MRA reported 407 (78.9\%) of the arteries to be either normal or with mild atherosclerotic irregularity, $66(12.8 \%)$ had moderate stenosis and $43(8.3 \%)$ were severely stenosed or completely occluded.
The highest proportion of severely stenosed arteries was in the RMCA $(17.4 \%, \mathrm{n}=15)$ followed by the LMCA (9.3\%). Detailed findings of the MRA are given in Table 1.

Of the 86 patients, 38 (44.2\%) had complete examinations where all 6 arteries of interest (LACA, RACA, LMCA, RMCA, LPCA, RPCA) were seen, 45 had incomplete assessments where at least one but not all arteries were visualized and there were 3 patients, all women, in whom not a single artery was visualized. Overall, there was an attempt to visualize a total of 516 arteries in 86 patients ( 6 arteries in each patient) through the TCD but they were successful in insonating only 375 (72.7\%) arteries. The insonation failure in men was $19.6 \%(\mathrm{n}=53)$ while it was $35.7 \%(n=88)$ in women. The arteries most successfully insonated were the MCAs $(91.7 \%$ RMCAs and $89.5 \%$ LMCAs) followed by the ACAs (65.1\% LACAs and $68.6 \%$ RACAs) while the PCAs were insonated least successfully (61.6\% in right $60.5 \%$ in left). Insonation success rate for each artery is given in Table 2 .

The findings of the sonography were categorized both via the peak velocity as well as the mean velocity to categorize the degree of stenosis as assessed by the TCD. Regardless of the criteria used, no artery was labeled as having $>50 \%$ stenosis by the TCD. This essentially gives us sensitivity and positive predictive values of $0 \%$ for all arteries using either criterion. Similarly both criteria

Table 2 The proportion of successful and unsuccessful insonations in each artery

\begin{tabular}{lcc}
\hline & Successful & Unsuccessful \\
\hline Right middle cerebral artery & $78(91.7 \%)$ & $8(9.3 \%)$ \\
Left middle cerebral artery & $77(89.5 \%)$ & $9(10.5 \%)$ \\
Right anterior cerebral artery & $59(68.6 \%)$ & $27(31.4 \%)$ \\
Left anterior cerebral artery & $56(65.1 \%)$ & $30(34.9 \%)$ \\
Right posterior cerebral artery & $53(61.6 \%)$ & $33(38.4 \%)$ \\
Left posterior cerebral artery & $52(60.5 \%)$ & $34(39.5 \%)$ \\
Total & $375(73.7 \%)$ & $141(27.3)$ \\
\hline
\end{tabular}

Table 1 Magnetic resonance angiography findings

\begin{tabular}{|c|c|c|c|}
\hline & $\begin{array}{l}\text { Normal/mild atherosclerotic } \\
\text { changes ( }<30 \% \text { stenosis) }\end{array}$ & $\begin{array}{l}\text { Moderately stenosed } \\
\text { (30-50\% stenosis) }\end{array}$ & $\begin{array}{l}\text { Severely stenosed } \\
\text { (>50\% stenosis) }\end{array}$ \\
\hline Right middle cerebral artery & $60(69.8 \%)$ & $11(12.8 \%)$ & $15(17.4 \%)$ \\
\hline Left middle cerebral artery & $67(77.9 \%)$ & $11(12.8 \%)$ & $8(9.3 \%)$ \\
\hline Right anterior cerebral artery & $71(82.6 \%)$ & $10(11.6 \%)$ & $5(5.8 \%)$ \\
\hline Left anterior cerebral artery & $70(81.4 \%)$ & $11(12.8 \%)$ & $5(5.8 \%)$ \\
\hline Right posterior cerebral artery & $70(81.4 \%)$ & $12(14.0 \%)$ & $4(4.7 \%)$ \\
\hline Left posterior cerebral artery & $69(80.2 \%)$ & $11(12.8 \%)$ & $6(7.0 \%)$ \\
\hline Overall & 407 (78.9\%) & $66(12.8 \%)$ & $43(8.3 \%)$ \\
\hline
\end{tabular}


also had an identical negative predictive value (93.3\%). A brief comparison on MRA and TCD findings is given in Table 3.

The proportion of stenosed vessels among arteries that were not successfully insonated was $12.7 \%$ which is higher than the proportion of stenosed or occluded vessels (8.3\%) among the visualized arteries.

\section{Discussion}

With the abundant data available on the prevalence and the magnitude of ICAD [6, 26-29] it is important to look at screening and diagnostic modalities that can be effective in reducing morbidity and mortality. This is one of the earlier studies to explore the use of intracranial Doppler among the South Asian population. Previous studies [20, 30-33] in other parts of the world regarding the TCD have had promising results. Although the sensitivity has been reported to be as low as $65 \%$ in some cases [20], a negative predictive value of over $90 \%$ would suggest that the Doppler can be used to screen out patients who would benefit from aggressive risk management [34]. Unfortunately, this study suggests the Doppler ultrasound is an ineffective tool for this purpose in the South Asian setting when done in a pragmatic fashion in real life patients admitted for stroke.

Since only 38 of the 86 patients had complete examinations, TCD appears to be an unreliable screening tool since most patients will then have to undergo further evaluation based on inconclusive results. Although previous studies [35, 36] have reported insonation failures, these failures are estimated to be between 10 and $30 \%$. Hashimoto et al. [37] reported a failure to visualize temporal windows in $29 \%$ of the subjects when he studied the Japanese population while another study, also in Japan, by Itoh [38] had a failure rate of around $22.8 \%$. Similarly, when Seidel used the color coded doppler in the German population, he failed to visualize the intracranial arteries in 20\% of cases [39]. One study in 2011 [40] in the United States reported an insonation failure of around $22.2 \%$ in 99 patients Interestingly, the study mentioned above quoted higher insonation failure rates for African Americans (47\%) compared to whites (15\%)

Table 3 Comparison of transcranial Doppler and magnetic resonance angiography findings

\begin{tabular}{|c|c|c|}
\hline \multirow[t]{2}{*}{ TCD } & \multicolumn{2}{|l|}{ MRA } \\
\hline & $>50 \%$ stenosis & $<50 \%$ stenosis \\
\hline$>50 \%$ stenosed & 0 & 0 \\
\hline$<50 \%$ stenosed & 25 & 350 \\
\hline Failed to insonate & 18 & 123 \\
\hline Total & 43 & 473 \\
\hline
\end{tabular}

when it used multivariate analysis. This would support the belief that difficulties that have been documented [19] using TCD, such as difficulty in visualizing temporal windows and fixating probe positions, are more applicable to certain populations compared to others and more specifically Asians and African Americans as compared to Caucasians.

What is also of note however, is that most studies [20, $33,41-44]$ that have studied the TCD have primarily looked at the MCAs while only some have studied the vertebrobasilar arteries [32], the PCAs [32, 45, 46] or all the arteries that were included in this study $[35,47]$. When we look at the failure rate of MCAs in our study $(<10 \%)$, it does become comparable to the other studies mentioned earlier. And so perhaps the only artery that had any results was the MCA but even this does not seem feasible.

The rate of insonation failures was higher in women as compared to men. Although this finding has not been encountered commonly, there has been at least one previous study [40] that reported a higher insonation failure rate in women compared to men. On the other hand, Hashimoto et al. [37] reported a much higher (84 vs. 52\%) rate of successful insonations in men compared to women.

The most significant result pertaining to the outcome of the ultrasound was the inability of the TCD to correctly detect any vessel as stenosed or occluded. This would rule out the TCD as a screening tool since it fails to identify high risk patients that need to be managed. The two criteria that were used to classify stenosis TCD findings, the PV and MV, both reported negative predictive values of $93.3 \%$. This would seem to be in line with previous studies [20] but it is in fact a reflection of the proportion of normal vessels and their of correct classification Hence, this does not have any importance in relation to identifying diseased vessels. This study therefore cannot be used to establish the superiority of one criterion over another nor does this have any importance when assessing the TCD as a screening tool.

This study is one of the first to look at the TCD in the South Asian population. However, it is a limited observation in a single center with a trained operator who had standardized training and audit. The strokes were classified with rigor and the images reviewed with MRA and radiology. Under these settings and clinical conditions it appears that the TCD is not a useful tool at all. Whether broad based population studies on community based patients would be different is an area of further investigation and these finding are limited to an inpatient type setting.

\section{Conclusions}

With the rapidly growing morbidity and mortality rates of stroke in this region, screening tools need to be devised 
that can identify high risk patients so that strokes may be prevented. This study evaluated the TCD as a potential screening tool for this purpose in a hospital setting.

\section{Additional file}

Additional file 1: Appendix 1. Reference standards for TCD performance.

\begin{abstract}
Abbreviations
ICAD: large artery intracranial atherosclerosis; TCD: transcranial Doppler; MRA: magnetic resonance angiography; WASID: warfarin aspirin symptomatic intracranial disease; SONIA: the stroke outcomes and neuroimaging of intracranial atherosclerosis; CCS: causative classification system for ischemic stroke; PV: peak velocity; MV: time averaged mean of the maximum velocity; PCA: posterior cerebral artery; MCA: middle cerebral artery; ACA: anterior cerebral artery; LPCA: left posterior cerebral artery; LMCA: left middle cerebral artery; LACA: left anterior cerebral artery; RPCA: right posterior cerebral artery; RMCA: right middle cerebral artery; RACA: right anterior cerebral artery; ICAVL: Intersocietal Commission for the Accreditation of Vascular Laboratories.
\end{abstract}

\section{Authors' contributions}

AKK conceptualized the study and organized it, reviewed this manuscript and wrote the first outline; HR, wrote the second draft, edited the paper and helped analyze the results; NM reviewed the paper and performed ultrasound evaluations; BA provided statistical support; $\mathrm{MJ}$ reviewed the paper and the data entry procedures; FW, SK classified the strokes for this study and reviewed this manuscript prior to publication. All authors read and approved the final manuscript.

\section{Author details \\ ${ }^{1}$ Stroke Service, Stroke Fellowship Program, International Cerebrovascular Translational Clinical Research Training Program, Fogarty International Center and The National Institute of Neurologic Disorders and Stroke, Section of Neurology, Department of Medicine, Aga Khan University, Stadium Road, Karachi 74800, Pakistan. ${ }^{2}$ Stroke Service, Section of Neurology, Department of Medicine, Aga Khan University, Karachi, Pakistan. ${ }^{3}$ Epidemiology and Bio- statistics, Section of Neurology, Department of Medicine, Aga Khan University, Karachi, Pakistan. ${ }^{4}$ Data Management Stroke Service, Section of Neurology, Department of Medicine, Aga Khan University, Karachi, Pakistan.}

\section{Acknowledgements}

This work was facilitated by the following: The Karachi Intracranial Stenosis Study was funded by a grant awarded to Ayeesha Kamran Kamal and Philippe M Frossard (formerly Dept. of Biologic and Biomedical Sciences, Aga Khan University) by the Higher Education Commission, Government of Pakistan, and No. 20-941/R\&D/07. Ayeesha Kamran Kamal was also the recipient of a seed money Grant from the University Research Council, Aga Khan University Hospital to initiate exploratory work that led to the elaborated study. Dr. Faisal Wadiwalla trained as neurovascular research fellow whose training was currently funded by Award Number D43TW008660 from the Fogarty International Center and the National Institute of Neurologic Disorders and Stroke. The funders had no role in study design, data collection and analysis, decision to publish, or preparation of the manuscript. The content is solely the responsibility of the authors and does not necessarily represent the official views of the Fogarty International Center, National Institute of Neurologic Disorders and Stroke or the National Institute of Health or the Higher Education Commission, Government of Pakistan.

The authors would like to acknowledge the patience, kindness, time and cooperation of all patients and their families who contributed to this study. We would also like to take this opportunity to acknowledge, Hina Tejani for their excellent secretarial support. In addition the stroke team would like to acknowledge the support of the Section of Neurology at AKUH who always facilitate logistically all research endeavors.

\section{Compliance with ethical guidelines}

\section{Competing interests}

The authors declare that they have no competing interests.

Received: 3 March 2014 Accepted: 22 July 2015

Published online: 11 August 2015

\section{References}

1. Gaziano TA, Bitton A, Anand S, Abrahams-Gessel S, Murphy A (2010) Growing epidemic of coronary heart disease in low- and middle-income countries. Curr Probl Cardiol 35(2):72-115

2. De Silva DA, Woon FP, Lee MP, Chen CP, Chang HM, Wong MC (2007) South Asian patients with ischemic stroke: intracranial large arteries are the predominant site of disease. Stroke 38(9):2592-2594

3. Feldmann E, Daneault N, Kwan E, Ho KJ, Pessin MS, Langenberg P et al (1990) Chinese-white differences in the distribution of occlusive cerebrovascular disease. Neurology 40(10):1541-1545

4. Kieffer SA, Takeya Y, Resch JA, Amplatz K (1967) Racial differences in cerebrovascular disease. Angiographic evaluation of Japanese and American populations. Am J Roentgenol Radium Ther Nucl Med 101(1):94-99

5. Nishimaru K, McHenry LC Jr, Toole JF (1984) Cerebral angiographic and clinical differences in carotid system transient ischemic attacks between American Caucasian and Japanese patients. Stroke 15(1):56-59

6. Sacco RL, Kargman DE, Gu Q, Zamanillo MC (1995) Race-ethnicity and determinants of intracranial atherosclerotic cerebral infarction. The Northern Manhattan stroke study. Stroke 26(1):14-20

7. Wong KS, Li H (2003) Long-term mortality and recurrent stroke risk among Chinese stroke patients with predominant intracranial atherosclerosis. Stroke 34(10):2361-2366

8. Viaro F, Farina FM, Onofri A, Meneghetti G, Baracchini C (2012) Symptomatic intracranial stenosis: a university hospital-based ultrasound study. Perspect Med 1(1-12):211-213

9. Fuster V, Stein B, Ambrose JA, Badimon L, Badimon JJ, Chesebro JH (1990) Atherosclerotic plaque rupture and thrombosis. Evolving concepts. Circulation 82(3 Suppl):|147-1159

10. Steve E, Roach KB, Biller J (2010) Atherosclerosis of the cervicocranial arteries, chap 7. Cambridge University Press, pp 105-117. doi:10.1017/ CBO9781139644235.010

11. Feldmann E (2005) Transcranial Doppler: evaluation of intracranial occlusive cerebrovascular disease: a methodological perspective. Semin Cerebrovasc Dis Stroke 5(2):93-105

12. Chimowitz MI, Kokkinos J, Strong J, Brown MB, Levine SR, Silliman S et al (1995) The warfarin-aspirin symptomatic intracranial sisease study. Neurology 45(8):1488-1493

13. Samuels OB, Joseph GJ, Lynn MJ, Smith HA, Chimowitz MI (2000) A standardized method for measuring intracranial arterial stenosis. AJNR Am J Neuroradiol 21(4):643-646

14. (1991) Beneficial effect of carotid endarterectomy in symptomatic patients with high-grade carotid stenosis. N Engl J Med 325(7):445-453

15. Walker MD, Marler JR, Goldstein M, Grady PA, Toole JF, Baker WH et al (1995) Endarterectomy for asymptomatic carotid artery stenosis. JAMA 273(18):1421-1428

16. Dion JE, Gates PC, Fox AJ, Barnett HJ, Blom RJ (1987) Clinical events following neuroangiography: a prospective study. Stroke 18(6):997-1004

17. Hobson RW, Weiss DG, Fields WS, Goldstone J, Moore WS, Towne JB et al (1993) Efficacy of carotid endarterectomy for asymptomatic carotid stenosis. N Engl J Med 328(4):221-227

18. Feldmann E (2009) Diagnosis and quantitation of intracranial stenosis. J Neuroimaging 19(Suppl 1):22S-24S

19. Alexandrov AV, Babikian VL, Adams RJ, Tegeler CH, Caplan LR, Spencer MP (1998) The evolving role of transcranial doppler in stroke prevention and treatment. J Stroke Cerebrovasc Dis 7(2):101-104 
20. Feldmann E, Wilterdink JL, Kosinski A, Lynn M, Chimowitz MI, Sarafin J et al (2007) The Stroke Outcomes and Neuroimaging of Intracrania Atherosclerosis (SONIA) trial. Neurology 68(24):2099-2106

21. GeoHive (2014) Cities: largest (without surrounding suburban areas) http://www.geohive.com/earth/cy_notagg.aspx. Cited 16 Jan 2014

22. Ay H, Benner T, Arsava EM, Furie KL, Singhal AB, Jensen MB et al (2007) A computerized algorithm for etiologic classification of ischemic stroke: the causative classification of stroke system. Stroke 38(11):2979-2984

23. Baumgartner RW, Mattle HP, Schroth G (1999) Assessment of $\geq 50 \%$ and $<50 \%$ intracranial stenoses by transcranial color-coded duplex sonography. Stroke 30(1):87-92

24. Intersocietal Accreditation Commission (2012) IAC standards and guidelines for vascular testing accreditation. Intersocietal Accreditation Commission, Ellicott City, MD, pp 29-32. http://intersocietal.org/vascular/ main/vascular_standards.htm. Accessed 8 Mar 2015

25. Gordis L (2009) Epidemiology. Medical. Elsevier/Saunder. https://books.google.com.pk/books/about/Epidemiology. html?id=GseHglbJo4gC\&redir_esc. Accessed 8 Mar 2015

26. Arenillas JF (2011) Intracranial atherosclerosis: current concepts. Stroke 42(1 Suppl):S20-S23

27. Gorelick PB, Wong KS, Bae HJ, Pandey DK (2008) Large artery intracranial occlusive disease: a large worldwide burden but a relatively neglected frontier. Stroke 39(8):2396-2399

28. Kasner SE, Chimowitz MI, Lynn MJ, Howlett-Smith H, Stern BJ, Hertzberg VS et al (2006) Predictors of ischemic stroke in the territory of a symptomatic intracranial arterial stenosis. Circulation 113(4):555-563

29. Wong LK (2006) Global burden of intracranial atherosclerosis. Int J Stroke 1(3):158-159

30. Camerlingo M, Casto L, Censori B, Ferraro B, Gazzaniga GC, Mamoli A (1993) Transcranial Doppler in acute ischemic stroke of the middle cerebral artery territories. Acta Neurol Scand 88(2):108-111

31. Cher LM, Chambers BR, Smidt V (1992) Comparison of transcranial Doppler with DSA in vertebrobasilar ischaemia. Clin Exp Neurol 29:143-148

32. Rorick MB, Nichols FT, Adams RJ (1994) Transcranial Doppler correlation with angiography in detection of intracranial stenosis. Stroke 25(10):1931-1934

33. Gerriets T, Goertler M, Stolz E, Postert T, Sliwka U, Schlachetzki F et al (2002) Feasibility and validity of transcranial duplex sonography in patients with acute stroke. J Neurol Neurosurg Psychiatry 73(1):17-20

34. Nahab F, Kingston C, Frankel MR, Dion JE, Cawley CM, Mitchell B et al (2013) Early aggressive medical management for patients with symptomatic intracranial stenosis. J Stroke Cerebrovasc Dis 22(1):87-91

35. Felberg RA, Christou I, Demchuk AM, Malkoff M, Alexandrov AV (2002) Screening for intracranial stenosis with transcranial Doppler: the accuracy of mean flow velocity thresholds. J Neuroimaging 12(1):9-14

36. Saqqur M, Shuaib A, Alexandrov AV, Hill MD, Calleja S, Tomsick T et al (2005) Derivation of transcranial Doppler criteria for rescue intra-arterial thrombolysis: multicenter experience from the interventional management of stroke study. Stroke 36(4):865-868
37. Hashimoto H, Etani H, Naka M, Kinoshita N, Nukada T (1992) Assessment of the rate of successful transcranial Doppler recording through the temporal windows in Japanese with special reference to aging and sex. Nihon Ronen Igakkai Zasshi 29(2):119-122

38. Itoh T, Matsumoto M, Handa N, Maeda H, Hougaku H, Hashimoto H et al (1993) Rate of successful recording of blood flow signals in the middle cerebral artery using transcranial Doppler sonography. Stroke 24(8):1192-1195

39. Seidel G, Kaps M, Gerriets T (1995) Potential and limitations of transcranial color-coded sonography in stroke patients. Stroke 26(11):2061-2066

40. Suri MF, Georgiadis AL, Tariq N, Vazquez G, Qureshi N, Qureshi Al (2011) Estimated prevalence of acoustic cranial windows and intracranial stenosis in the US elderly population: ultrasound screening in adults for intracranial disease study. Neuroepidemiology 37(1):64-71

41. Arenillas JF, Molina CA, Montaner J, Abilleira S, Gonzalez-Sanchez MA, Alvarez-Sabin J (2001) Progression and clinical recurrence of symptomatic middle cerebral artery stenosis: a long-term follow-up transcranial Doppler ultrasound study. Stroke 32(12):2898-2904

42. Burgin WS, Malkoff M, Felberg RA, Demchuk AM, Christou I, Grotta JC et al (2000) Transcranial doppler ultrasound criteria for recanalization after thrombolysis for middle cerebral artery stroke. Stroke 31(5):1128-1132

43. Chen J, Wang L, Bai J, Lun Z, Zhang J, Xing Y (2014) The optimal velocity criterion in the diagnosis of unilateral middle cerebral artery stenosis by transcranial Doppler. Cell Biochem Biophys 69(1):81-87

44. Telman G, Namestnikov O, Kouperberg E, Sprecher E, Yarnitsky D (2008) Ischemic middle cerebral artery stroke missing the tissue plasminogen activator time window: transcranial Doppler evaluation. J Stroke Cerebrovasc Dis 17(6):366-369

45. Jatuzis D, Zachrisson H, Blomstrand C, Ekholm S, Holm J, Volkmann R (2000) Evaluation of posterior cerebral artery blood flow with transcranial Doppler sonography: value and risk of common carotid artery compression. J Clin Ultrasound 28(9):452-460

46. Tian JW, Sun LT, Zhao ZW, Gao J (2006) Transcranial color Doppler flow imaging in detecting severe stenosis of the intracranial vertebral artery: a prospective study. Clin Imaging 30(1):1-5

47. Wong KS, Li H, Chan YL, Ahuja A, Lam WWM, Wong A et al (2000) Use of transcranial Doppler ultrasound to predict outcome in patients with intracranial large-artery occlusive disease. Stroke 31(11):2641-2647

\section{Submit your next manuscript to BioMed Central and take full advantage of:}

- Convenient online submission

- Thorough peer review

- No space constraints or color figure charges

- Immediate publication on acceptance

- Inclusion in PubMed, CAS, Scopus and Google Scholar

- Research which is freely available for redistribution

Submit your manuscript at

www.biomedcentral.com/submit

C Biomed Central 